\title{
HUMAN INTELLIGENCE ANALYSIS AND DETECTING SCENARIOS USING ARTIFICIAL INTELLIGENCE BASED ON HUMAN COMPUTER INTERACTION IN EDUCATION SYSTEM
}

\author{
Akash Dilip Hatalge \\ Department of Computer Science and Engineering \\ Walchand College of Engineering (An Autonomous Institute) \\ Sangli, India
}

\begin{abstract}
It is different from the situation that people have just experienced normal information from general websites. Users of an educational web application for teaching as faculty and students need more communication with each other. That means they desperately need to communicate with mediators like computers and other resources. Therefore, research conducted on the design of human computers takes a huge amount of value. In this paper, a user model of Educational Web Application is concluded. The Web Application includes that Facial Recognition for login, attendance and to see the student's behavior in the classroom by continuous monitoring. Knowledge trees and tests are designed for better understanding and to improve yourself in particular or all subjects. The aim of the paper is to develop a system to manage and maintain sentiments and detecting student's behavior by humancomputer interaction. We propose a software framework to monitor boundaries, analyze them and support users to see how they interact in conversations or lectures and manage their emotions.
\end{abstract}

Keywords - HCI, SOA, Website, Facial Expression, Concentration Level

\section{INTRODUCTION}

The unintended effects of education include upgrading the social economy, which eventually affects the national economy [5]. Technology itself is constantly being developed and is making an important contribution to the development of a learning and teaching process that is characterized by globalization [5]. Educational web application refers to what the teachers and student are like divided into time or space but interacting with each other through technologies such as the Internet, Computer, and multimedia. It is not only the inevitable consequences of social, economic, and educational

\author{
Dr. Bashirahamad F. Momin \\ Department of Computer Science and Engineering \\ Walchand College of Engineering (An Autonomous Institute) \\ Sangli, India
}

development itself but also the expression of social needs with education. An educational web application uses a good environment for learning and communication programs and gives everyone a chance to learn lifelong information.

In recent years, the Government of India had required" capture all the resources undergoing across space and time" and point up that the progression of modern education is a strategy to rate the pursuit of good education under educational resources. And some of the colleges and universities had constructed and designed their educational web application.

Although, there are quite many necessities and issues in the current online education system. For example, as many existing websites are produced with low-frequency density, it is hard to make connections and split resources/materials between different websites or between the various features on that website. In addition to the points mentioned above, the Education web app has unique features compared to the standard website. In contrast to the situation where people simply find information on standard websites, teachers and students use a web application network that requires multiple connections. That means they desperately need to communicate with a mediator such as a computer and other resources. Research into the structure of human-computer communication is therefore of great importance. In this paper, by analyzing the user's feelings when receiving information, the user's model accurately predicts the user's real purpose for the user's focus in the classroom. Tests and suggestions are designed to improve themselves, especially in all subjects. This website is designed according to the modules. To prove the quality and the functionality of the website, the test was conducted by Indian students of up to 20 people.

\section{Literature REVIEW}

(Peng Bian, Yi Jin, Nairen Zhang) This study aims to design a website for students and teachers to get more communication with this platform. This paper summarizes the 


\section{International Journal of Engineering Applied Sciences and Technology, 2021 \\ Vol. 6, Issue 3, ISSN No. 2455-2143, Pages 91-95 \\ Published Online July 2021 in IJEAST (http://www.ijeast.com)}

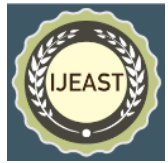

only Human-Computer Interaction strategies for distance education websites as a mode of interactivity, the principle of interaction design, and activity of interaction design [3]

(Gong Chao) This paper summarizes the concepts of computer interface and human-machine systems, communication, and communication learning of humancomputer systems [1]. Under these orders, it suggested that computer-aided design and user experience, and other critical points and principles honored during the design process, which gives to others a visual interface for the basis of humanmachine design systems and has the value of some guidance. The main ideas of this paper are to spell out how it is done to enhance human- machine systems, how they are made equipment to get used to working better and better for people, thus bringing in people, equipment, and the environment in a united relationship [1].

\section{METHODOLOGY}

\section{A. Design of Service Oriented Architecture}

Service-Oriented Architecture is a type of business-based technology that makes sense, transforming business modeling and technology structures. It represents a scalable, open, fast, and engaging structure. Technical support of HCI design provided by the method of service-oriented architecture.

\section{B. Sentiment Analysis}

When the user enters into the website it will ask to register for the new members and the login page for the registered user Registration page ask for the User which is students a teach for Image for face recognition, Full Name, Password Contact Number, Email. After the successful registration login is done by face detection.

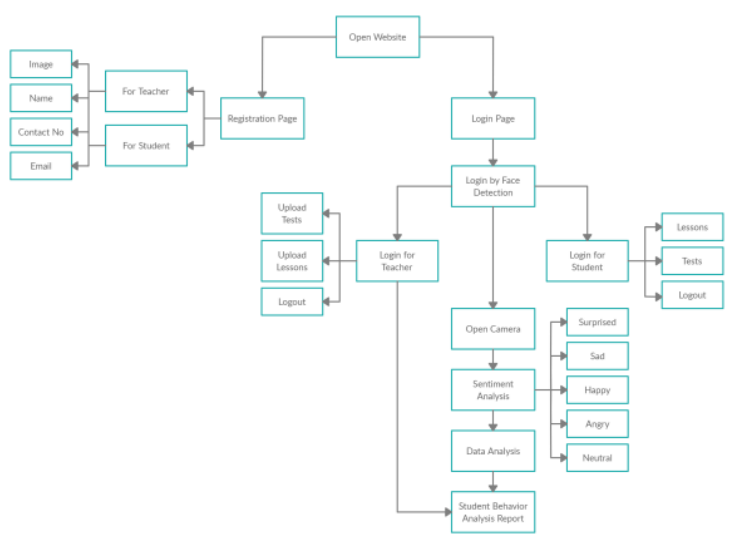

Fig. 1. Flowchart Sentiment analysis of the user.

After the successful login with the account camera of the system will get started for continuous monitoring of the user. It will capture the image and analyze the sentiments of the user also it will recognize the face of the user. The purpose of the facial expression is to verify that the user is concentrated in lectures or not. After analysis, all the data of facial expressions of the users are stored in a database which will only be displayed on the teacher side. Also, we have drawn a pie chart for graphical representation. The teacher can download the report of the student in PDF, DOC, and XML format. The report of the students is separated by date-wise and month- wise.

\section{The Relationship and Interaction between user layer, ap- pearance layer and database layer.}

From Fig2., we know that communication can be summa- rized between the user (including student, teacher, and system administrator) and visual layer (course pages, homework, tests, report) with software and hardware.

At the beginning of an HCI for Educational Web Application process, we should know the mainframes of the website that is delivered to students. Then the resources of the course, resources of the test, resources of the information, and other resources should be supplied to the structural content of the network [3]. In the designing process, we have to decide in which way it makes the content interact with the user by the method of SOA [3] (Service Oriented Architecture). After this stage at the visual layer, we have to take efforts to feather the interface of the Educational Web Application. At last, the latest support and supplementary builds are needed after the websites are deployed.

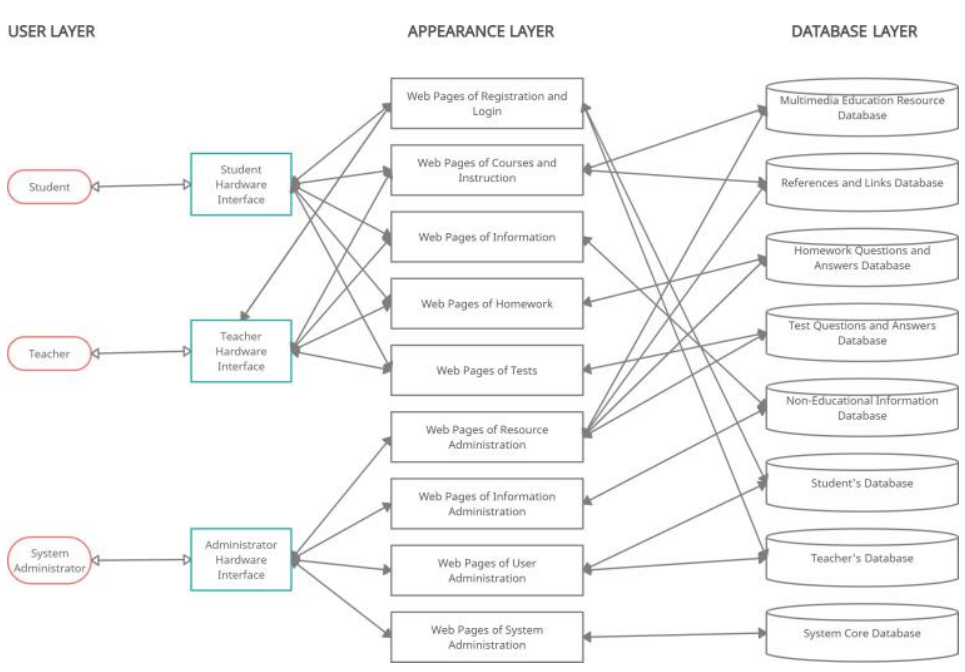

Fig. 2. Interaction and Relationship between user layer and visual layer.

\section{Questionnaire on the Lectures}

The examination encourages students for learning and working. The questionnaire will help the user to improve them- selves on a particular topic. With this, a user is able to know his level of skills, Knowledge and his/her performance. A single teacher can determine the progression or improvement of many students at once by taking a single examination for all. It also measures a teacher's capability and insufficiency and if any subject is re-taught or explained differently. 


\section{International Journal of Engineering Applied Sciences and Technology, 2021 \\ Vol. 6, Issue 3, ISSN No. 2455-2143, Pages 91-95 \\ Published Online July 2021 in IJEAST (http://www.ijeast.com)}

\section{E. Face Detection}

While doing registration of the student, the system automatically captures the frames of the student which are stored in the database. When a student trying to login into the system, it will compare the live frame with the frames stored in the database, if the frames matched then you will be logged in to the system and if the frames are not matched then it will not log you in into the system. Fig. 3 shows the face detection of the user for login.

\section{F. Facial Expression}

After the successfully login with the account camera of the system will get started for continuous monitoring of the user. It will capture the image and analyze the sentiments of the user. Facial expression is one or more movements under

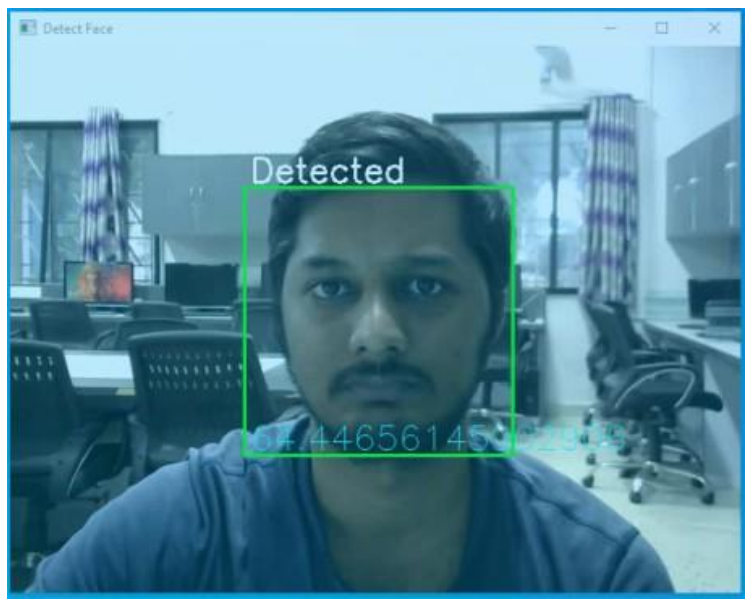

Fig. 3. Face Detection of the user for login.

the facial skin. According to one set of controversial theory, these movements convey the human condition to the observer. Facial expression is a non-verbal communication method. We will detect facial expression of the student to analyze his/her sentiments. By using this method, we analyze the concentration level of the user by using its facial expression. Derived from this study, we aim to come up with the effect of sentiments in that concentration level.

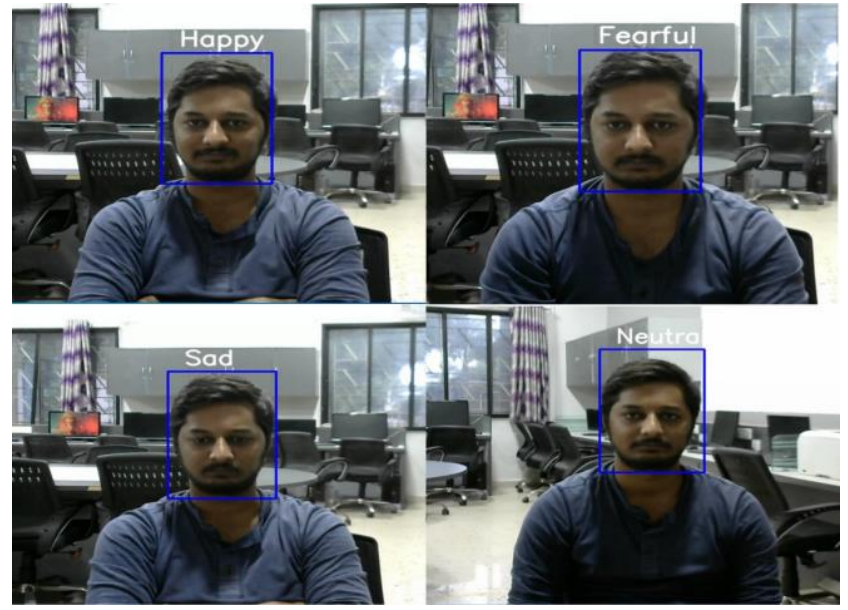

Fig. 4. Facial expression of the user.

\section{OUR WORK}

It is different with the situation that people have just experienced normal information from general websites. Users of an educational web application for teaching as faculty and students require more contact with each other. That the way they are in more requisite of relation with mediator such as computer and other resources [3]. The number of cyber-attacks can be perform on normal educational website. To overcome this issue HCI comes as a solution that will help users (students and teachers) achieve the most intimate relationships between humans, computer and the environment. Machine Learning analyzes user's behaviors in terms of information acquisition, user model can predict student's real purpose is based on imagination and personal action design solutions for computer on educational web application, which is related to visual design ideas, user research method, psychology and computer science.

There are basic six types of human emotions: Anger, Sadness, Happiness, Neutral, Fear and Surprise. System recognize facial emotions and give the final output of actual facial expression. Then it will store all the expressions per frame in the database. By taking all the facial expressions values system draw the pie chart of each user. It will help the teacher to analyse user's behavior easily. We are assuming that the neutral emotion has the highest concentration level (i.e. if a user has the neutral emotion then the user is more engrossed). So, first of all the system requirements are minimum $4 \mathrm{~GB}$ of ram, $5 \mathrm{~GB}$ of free disk space and 64 bit CPU (Intel/AMD), Web-camera or in-built camera in laptop, Modern Operating System - Windows7 or later / Mac OS X 10.11 or higher, Linux. Software needs to install are Python3 with pip3 version, CV2, OS library, Chrome Driver, Haarcascade, Django. Firstly, when entering into web application, data is collected by the camera and questionnaire and it will store in database. Face detection is done by the camera and the value will be store in the database. Sentiment 


\section{International Journal of Engineering Applied Sciences and Technology, 2021 \\ Vol. 6, Issue 3, ISSN No. 2455-2143, Pages 91-95 \\ Published Online July 2021 in IJEAST (http://www.ijeast.com)}

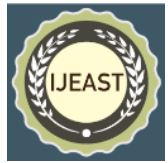

will detect by camera and the value will be store in database. Evaluation will be manage based on face recognition and sentiment analysis. The Web Application system as portal developed by using Django. Tests are managed to analyze how much student understand the concept this will help to improve the strength of the user in that particular subject or topic. Knowledge tree is designed for better understanding of the topic for the student.

\section{RESUlts AND Discussion}

In this study, Pie chart of the user shows the percentage of the sentiments of the user, it helps to check the concentration level of the user.

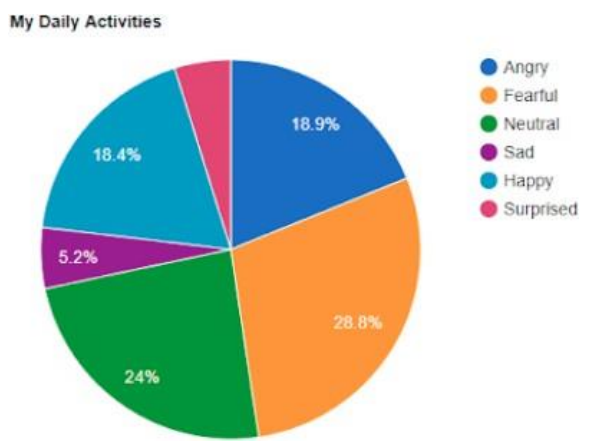

Fig. 5. Emotion Log of the User

Fig. 5 shows the Pie chart of the user's sentiment analysis. Graphical results will help to analyze the records. This chart will help the teachers to analyze the behavior of the student. By this facial expression, system check the concentration of the student.

It shows how easy e-learning can be used by users, easy to read so that users feel enjoyable using e-learning. Therefore, it is very important that the developers of the e-learning app are able to pay awareness to the practicalities so that the e-learning can have a positive impact on the users.

1) High Concentration Level: As student emits neutral emotion pose, we determine it as a high concentration level i.e. the student who has percentage above 75 has high concentration [6].

2) Medium Concentration Level: The Medium Concentration Level is determined as the level in which peak value is moderate. The peak value is between $45 \%$ to $75 \%$ In this level of concentration, along with neutral emotion, student will show the other emotions too on his face.

3) Low Concentration Level: At low concentration level, student shows wide range of emotions, but never has feelings of neutral emotion or very less neutral emotion. At this level, due to various outside factors, the reader does not pay his concentration to the content instructed by the teacher. The implemented service will not reach its target. The main objective will be to eliminate this level, and therefore, build on the relation between the student and the learning materials. The curriculum will boost if we are able to withdraw this level.

\section{A. Login Time Comparison}

\begin{tabular}{|l|l|}
\hline Website & Login Time \\
\hline Udemy & $5-10$ Seconds \\
\hline Coursera & $5-10$ Seconds \\
\hline Byju's & $10-15$ Seconds \\
\hline Whitehat jr & $15-20$ Seconds \\
\hline $\begin{array}{l}\text { WCE Educational Web } \\
\text { Application }\end{array}$ & $1-3$ Seconds \\
\hline
\end{tabular}

TABLE I

LOGIN TIME COMPARISON TABLE

We have done a face login system in this work, it requires less than 3 seconds to login into the system. Table 1 shows the comparison between other web applications and WCE web application login time. It is clearly showing that the WCE login system needs a minimum amount of time to login into the system, it helps to save time in login also reduces efforts of typing of email and password.

\section{B. Real-time analysis}

We have used Opencv's Haarcascades to detect the face of the student from the webcam video feed. Then we analyze the facial sentiments of the student using our CNN model. Real-time analysis best illustrates our model strengths: they were neutral, happy, fearful, sad, surprise generally angry were generally welldetected. Analysis was a very important factor in the model's performance.

\section{CONCLUSION}

From this research, this can be seen teachers and students searching for educational web application need to much con- tact with each other. So research into the design of human- computer interactions takes a lot importance. In this paper, we represent the features of user model; conclude the figure (student, teacher and system administrator) of educational web application. By analysing student facial expression, system check the concentration level of the student. The ultimate aim is to gain consensus interaction between computer, human and environment for our hard work.

we have proposed a system to assess student overcrowding in the e-learning environment, by analyzing student feelings. This proposed system consists of three main steps, first is the student's emotions which are captured by the camera. In the second step, the live video of the student is analyzed to get the student's live emotions and in the third step, this sentiment is processed to get the final detection that is the concentration level of the student. 


\section{REFERENCES}

[1]Gong Chao, "Human-Computer Interaction: Process and Principles of Human-Computer Interface Design,'International Conference on Com- puter and Automation Engineering, 2009.

[2]S. Lokesh,G. Balakrishnan,S. Malathy,K. Murugan"Computer Interac- tion to Human through Photorealistic Facial Model for Inter-process Communication,"2010 Second International conference on Computing, Communication and Networking Technologies.

[3]Peng Bian, Yi Jin,Nairen Zhang "Research on HumanComputer Inter- action Design for Distance Education Websites,"The 5th International Conference on Computer Science and Education Hefei, China. August 24-27, 2010.

[4]Zhigang Fang,Weibin Luo,Jie Xu "A Structure for Children-Oriented Human Computer Interaction,"Fourth International Workshop on Advanced Computational Intelligence Wuhan, Hubei, China; October 19- 21, 2011.

[5]Yogi Udjaja,Yasinta Indrianti,Osama Agami Rashwan,Samuel Anindyo Widhoyoko,Sasmoko "Designing Website E-Learning Based on Integration of Technology Enhance Learning and Human Computer Interac- tion,"2018 2nd International Conference on Informatics and Computa- tional Sciences (ICICoS).

[6]Prabin Sharma, Meltem Eseng önül, Salik Ram Khanal,Tulasi Tiwari Khanal, Vitor Filipe, and Manuel J. C. S. Reis1, "Student Concentra- tion Evaluation Index in an E-learning Context Using Facial Emotion Analysis", Springer Nature Switzerland AG 2019 